\title{
Sialendoscopy-assisted transfacial removal of parotid calculi
}

\author{
L'asportazione transfacciale scialoendoscopico-assistita dei calcoli parotidei \\ A.J. HILLS ${ }^{1}$, A.M. HOLDEN², M. McGURK³ \\ ${ }^{1}$ Department of Oral and Maxillofacial Surgery, William Harvey Hospital, Ashford, Kent, UK; ${ }^{2}$ Department of \\ Oral and Maxillofacial Surgery, Gloucestershire Royal Hospital, Gloucestershire, UK; ${ }^{3}$ Department of Oral and \\ Maxillofacial Surgery, Guy's Hospital, London, UK
}

\section{SUMMARY}

Superficial parotidectomy has significant morbidity, and minimally invasive techniques have therefore been developed, including those involving sialendoscopy, to remove sialoliths and preserve the gland along with its function. The size, mobility and location of the sialolith, alongside the presence of strictures, all dictate management. We outline basic treatment paradigms and describe two sialoendoscopyassisted surgical procedures developed for treating stones, one intraoral and one extraoral.

KEY WORDS: Sialolith • Sialendoscopy $\bullet$ Masseter $・$ Stensen's duct $\bullet$ Parotid

\section{RIASSUNTO}

La diffusione delle tecniche minimamente invasive per il trattamento dei calcoli salivari, quali la scialoendoscopia, ha permesso di ottenere un maggior tasso di preservazione della funzionalità ghiandolare, evitando le significative morbidità notoriamente associate alla parotidectomia superficiale. La scelta terapeutica è condizionata dalla dimensione, mobilità e posizione del calcolo così come dalla presenza di stenosi duttali. Verranno descritti i principi terapeutici inerenti la patologia litiasica, nonché due tecniche scialoendoscopico-assistite di rimozione dei calcoli salivari: la prima per via intra-orale, la seconda per via extra-orale.

PAROLE CHIAVE: Calcoli salivari $\bullet$ Scialoendoscopia $\bullet$ Massetere $\bullet$ Dotto di stenone $\bullet$ Parotide

Acta Otorhinolaryngol Ital 2017;37:128-131

\section{Introduction}

The foremost inflammatory disorder of the major salivary glands is obstructive sialadenitis, of which the most common cause is sialolithiasis ${ }^{1}$. The incidence of symptomatic salivary calculi is approximately 59 cases per million per annum ${ }^{2}$, with a clinical prevalence of $0.45 \%{ }^{3}$. Of these, parotid stones account for approximately 5-10\% 45 . Patients with blocked ducts can develop obstructive sialadenitis, presenting with "meal-time syndrome," a recurrent painful peri-prandial swelling of the affected gland which is frequently associated with fever and purulent discharge from the papilla as a result of superimposed bacterial infections ${ }^{67}$. Parotid sialoliths in the duct proximal to the anterior masseteric boarder have traditionally been treated with superficial parotidectomy, which has significant morbidity. The primary concern is damage to the facial nerve, with up $16 \%-38 \%$ of patients experiencing temporary weakness, and approximately $9 \%$ having some degree of permanent weakness ${ }^{89}$. Minimally invasive techniques have therefore been developed, including those involving sailendoscopy, to remove sailoliths and preserve the gland along with its function. Micro-endoscopy has been used in various guises for the management of salivary gland disease since $1991^{10}$. Its ability to directly visualise the duct has aided therapeutic interventions and offered additional diagnostic benefits by enabling direct visual assessment of the ductal lining. This facilitates the identification of obstructions not readily identifiable on radiology, such as radiolucent sailoliths, polyps, stenosis and mucous plugs.

\section{Anatomy}

The parotid glands lie in the preauricular region with the bulk of the gland overlying the masseter. The gland extends from the zygomatic process and mastoid process, and wraps around the posterior and inferior boarders of the mandible. They are the largest of the salivary glands, measuring approximately 46 x $37 \mathrm{~mm}$, being longer in their cranio-caudal axis ${ }^{11}$. The facial nerve transverses through the parotid gland, the plane of which divides it into superficial and deep parotid lobes, the superficial lobe being the larger accounting for two-thirds of the gland. Stensen's duct drains the parotid and is approximately 7 $\mathrm{cm}$ long, following a line drawn from the tragus to the midpoint of the upper lip. After the duct forms in the body 
of the gland, it exits through the hilum, bending acutely to pass medially into the tail of the parotid. As the duct exits the tail then the buccal branch of the facial nerve runs both parallel and in close proximity to it for approximately 2.5 $\mathrm{cm}$, with the nerve laying inferiorly in $75 \%$ of cases, but crossing to lie superiorly in up to $25 \%{ }^{12}{ }^{13}$. Both duct and nerve travel along the superficial surface of the masseter muscle before at its front edge the duct takes a right-angle turn medially to penetrate the buccinator and oral mucosa, exiting opposite the maxillary second molar intraorally. The nerve continues anteriorly towards the orbicularis oris muscle. The diameter of Stensen's duct varies along its length, ranging between $1.4 \mathrm{~mm}$ and $0.5 \mathrm{~mm}$ depending on the site (proximal $=1.4 ;$ middle $=1.2$; distal $=1.4$; ostium $=0.5)^{14}$. The narrow middle portion can be explained by the course of the duct through the buccinator muscle and in part helps explain the frequency of stone impaction in this region. Approximately $20 \%$ of these symptomatic parotid sialoliths are located within Stensen's duct ${ }^{1516}$, and a number of larger stones (4-7mm) can travel distally to lie near the punctum. Due to the tortuous nature of the ducts stones collect at three distinct regions where the duct changes direction, the masseteric edge $(23 \%)$, preauricular region $(42 \%)$ and the hilum $(35 \%){ }^{17}$.

\section{Investigation}

The mainstay of investigation is ultrasound, which can also visualise strictures if a duct is dilated with a sialogogue such as a vitamin $\mathrm{C}$ tablet prior to imaging. If a clear distinction is required, then formal sialogram is preferable. Small stones close to the ostium may, however, be best demonstrated by soft tissue dental X-ray. CT scans have too many radio-opaque artifacts to be reliable and MRI sialography, though accurate, seems extravagant when the vast majority of information can be gained by US and endoscopy.

\section{Treatment paradigms}

The size, mobility and location of the sialolith, alongside the presence of strictures, all dictate management ${ }^{18}$. Of these, stone size is all-important (Fig. 1). Those up to 4 $\mathrm{mm}$ can be drawn down and removed by basket if in a suitable position. However, some small stones may not be in the main duct but a sub-duct, which can have restricted access. One must bear this in mind when using sialendoscopy and radiological approaches as injudicious lavage may inadvertently wash stones back into these sub-ducts making them irretrievable by these methods. Moderately sized stones $5-8 \mathrm{~mm}$ in diameter can potentially be targeted by lithotripsy. Until recently only the extra corporeal shock wave lithotripsy (ECSWL) was available. This was expensive and only a few machines were active in Europe, and therefore the treatment was not available to the aver-

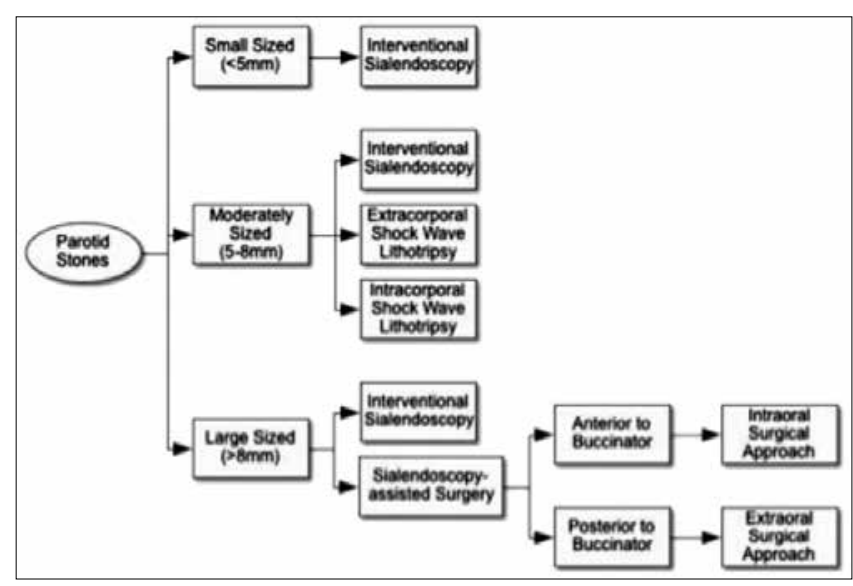

Fig. 1. Treatment paradigms.

age patient. A new intra-corporal devise is now available that is both affordable and effective. Most stones up to about $8 \mathrm{~mm}$ can now be targeted, with good results in selected cases ( $>70 \%$ cure). Stones larger than $8 \mathrm{~mm}$ that are in the descending portion of the duct or locked behind strictures fall to the realm of sialendoscopy-assisted surgery. The latter is important as the presence of a stricture distal from the stone prevents fragments moving down stream, and if surgery is deployed can lead to sialoceles. If extremely committed, one can try to dilate strictures and then pull stones through this segment, but this requires dedication, perseverance and patience, qualities few surgeons possess. The fundamental principal that has evolved through experience is that the punctum should not be violated, except very superficially, to release a stone that is already projecting from the orifice. Such an incision is not associated with stricture, but further dissection and incision of the punctum towards the buccinator muscle leads to a troublesome stricture. If a stone has to be retrieved through surgery, then there is a therapeutic divide based on anatomical position. This is due to the masseteric bend to the ostium that prevents stones anterior to it from being accessed from a pre- auricular method, and stones near the hilum similarly being blocked from an intraoral approach. Two sialoendoscopy-assisted surgical procedures have been developed for stones at these differing sites. The anterior boarder of the masseter delineates the posterior limit for an intraoral approach, more proximal to which an extraoral approach is used. Both are usually performed as a day case under general anaesthetic.

\section{Intraoral approach to parotid stones}

A minimally invasive transoral approach is used where the stone sits between the ostium and the anterior boarder of the masseter muscle. The endoscope is introduced to the duct and a semilunar incision is made through the mucosa $1 \mathrm{~cm}$ anterior to the parotid punctum, enabling 
lateral dissection between the buccal mucosa and buccinator muscle (Fig. 2). The duct, once cannulated by the endoscope, can be identified by palpation or the light at the tip of the scope and traced back as far as the anterior aspect of the masseter muscle. The duct is then carefully skeletonised by blunt dissection on either side of the duct. The latter comes into view as the soft issues around it are parted. Once the stone is located a longitudinal incision is made over the stone to deliver it (Fig. 3). Next, the endoscope is advanced to ensure no additional stones are present in the duct system. The gland is irrigated with normal saline before the small incision is closed with 6.0 vicryl rapide. The duct is ideally closed with the endoscope or lacrimal dilator lying within the lumen to ensure the lumen remains patent. The semilunar incision is closed with interrupted absorbable sutures. The advantage of this approach is that any leakage of saliva from the surgical

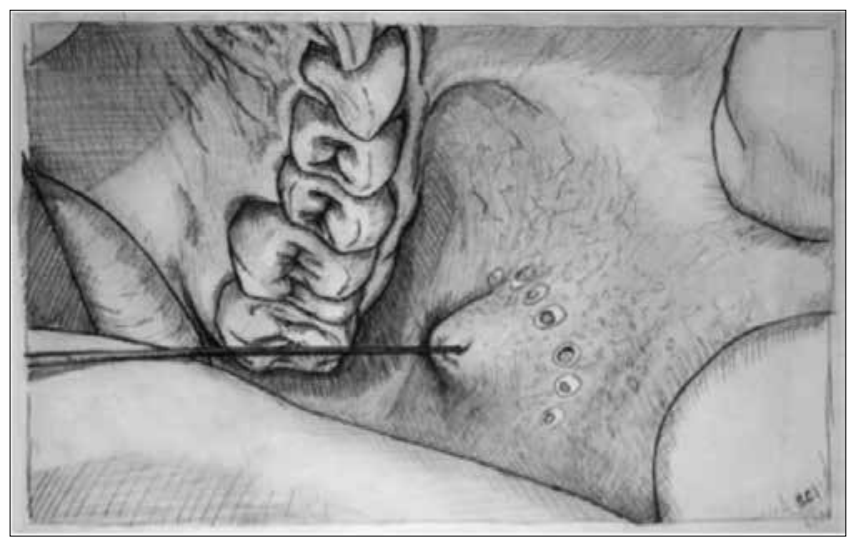

Fig. 2. Cautery marking the semilunar incision site on buccal mucosa approximately $1 \mathrm{~cm}$ anterior to the opening of the duct. The basket can be used to provide gentle traction.

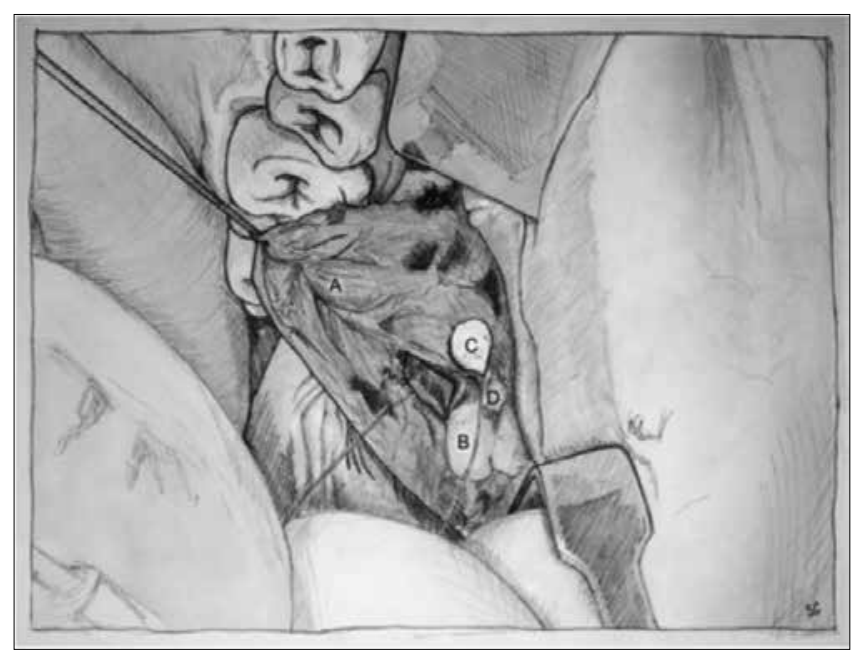

Fig. 3. Reflection of the mucosal flap with buccinator muscle lying medial (A) and buccal fat pad lateral (B) revealing the skeletanised duct with sialolith visible (C). Note the sutures used to both define the duct and provide traction to aid recannulation upon the sialolith's removal (D). site does not collect in the wound forming a sialocele, but empties spontaneously into the oral cavity. This situation is very uncommon. The procedure is associated with minimal side effects.

\section{Extraoral approach to parotid stones}

A stone that lies in the immediate preauricular area is first located with a salivary endoscope to confirm its position and is marked on the skin surface as a surgical guide. A Redon or modified Blair incision is then used to reflect the preauricular skin incision and expose the parotid fascia. The buccal branch of the facial nerve is quite superficial and usually comes into view once the parotid fascia is divided over the duct. A retrograde dissection along the buccal nerve shows that it passes superficial to the descending limb of the parotid duct and as this branch of the facial nerve is traced back towards the main trunk (the main trunk is never exposed or visualised) it helps to define the anatomy of the descending duct. The sialendoscope is then introduced into the duct and passed along the lumen until the stone is seen. Once the stone is found the light source to the endoscope is turned to maximum and the glow from the tip guides the surgeon on to the parotid duct. The duct is skeletonised at this location and once the stone is palpated a small longitudinal incision over its surface ensures its release. The endoscope is withdrawn from the mouth and inserted through the preauricular skin incision to inspect the descending portion of the duct to make sure no secondary stones are present. The duct is then irrigated before closing the incision in the wall with 6.0, the capsule with 4.0 vicryl rapide and the skin is closed as per the surgeon's preference. Patients are discharged with a pressure dressing and a 1-week course of antibiotics. The technique builds on that developed by Baurmarsh et al ${ }^{19}$ where the stones were first localised through plain radiographs and high-resolution ultrasound, before a horizontal skin incision was made directly over the calculus to deliver the stone. This technique was limited to larger, more superficial stones, towards the anterior border of the masseter muscle. The down side is that it frequently leaves an obvious scar on the cheek.

\section{Complications}

Over the last 9 years (2005-2014), 115 patients have been treated with 130 stones using the endoscopic assisted technique, with a successful stone retrieval rate of $98 \%$ ( $85 \%$ extraoral: $15 \%$ intraoral). Of these, $51 \%$ had undergone failed attempts at retrieval using conventional methods prior to using these techniques. Post-operative complications occurred in $23 \%$ (25 extraoral, 1 intraoral) cases, these included sialocele (14 cases), pre-auricular sensory deficit (7 cases), transient facial nerve weakness ( 5 cases), post-operative infection ( 5 cases) and fistula 
formation ( 2 cases). These post-operative complications were most commonly seen with the extraoral approach and were in keeping with the nature of the approach with dissection into the parotid. No complication was troublesome. Sialoceles all responded within 10 days to hyoscine tablets, intermittent aspiration and pressure dressing. The cause was a stricture downstream from the incision in the duct, these should be dilated prior to closing the duct incision. Altered sensation always occurs when lifting the pre-auricular skin and resolves slowly over time. The transient weakness was to the muscles of the upper lip due to tension on the buccal nerve. The two fistulae were a variation on the sialocele and were treated in the same way.

\section{Long-term results}

The endoscope-assisted technique has a high success rate $(97 \%)^{17}$. Late results were assessed by a postal survey at a mean of 44 months postsurgery confirmed the value of the technique with $89 \%$ of patients completely asymptomatic, $7 \%$ had a degree of residual meal time syndrome and only $4 \%$ had further incidences of sialadenitis. Significantly, no patient had persistent facial weakness or had gone on to require a parotidectomy.

\section{Conclusions}

Sialoendoscopically-assisted retrieval of parotid stones through an intraoral or extraoral approach is a practical option for the management of larger or impact stones that are not amenable to other endoluminal treatments. They have a high incidence of successful stone retrieval and a low occurrence of long-term complications whilst avoiding the need for parotidectomy with associated morbidity.

\section{Acknowledgements}

Medical illustrations by Dr Simran Chana.

\section{References}

1 McGurk M, Combes J. Endoscopic-assisted management of parotid stones. Controversies in the management of salivary gland disease. $2^{\text {nd }}$ ed. Oxford: Oxford University Press; 2013. p. 307.

2 Escudier MP, McGurk M. Symptomatic sialadenitis and sialolithiasis in the English population, an estimate of the cost of hospital treatment. Br Dent J 1999;186:463-6.
3 McGurk M, Escudier MP, Brown JE. Modern management of salivary calculi. Br J Surg 2005;92:107-12.

4 Hupp JR, Ellis E, Tucker MR. Contemporary oral and maxillofacial surgery. $5^{\text {th }}$ ed. St. Louis, Mo.: Mosby Elsevier; 2008. p. 407-409.

5 Capaccio P, Gaffuri M, Pignataro L. Sialendoscopy-assisted transfacial surgical removal of parotid stones. J Craniomaxillofac Surg 2014;42:1964-9.

6 Escudier MP. The current status and possible future for lithotripsy of salivary calculi. In: Pregrel M, editor. Atlas of oral and maxillofacial surgery clinics of North America. Philadelphia, PA: Saunders; 1998. p. 117-132.

7 Capaccio P, Torretta S, Ottaviani F, et al. Modern management of obstructive salivary diseases. Acta Otorhinolaryngol Ital 2007;27:161-72.

8 Owen ER, Banerjee AK, Kissin M, et al. Complications of parotid surgery: the need for selectivity. Br J Surg 1989;76:1034-5.

9 Mra Z, Komisar A, Blaugrund SM. Functional facial nerve weakness after surgery for benign parotid tumours: a multivariate statistical analysis. Head Neck 1993;15:147-52.

$10 \mathrm{Katz}$ PH. Endoscopy of the salivary glands [in French]. Ann Radiol (Paris) 1991;34:110-3.

11 Dost P. Ultrasonographic biometry in normal salivary glands. Eur Arch Otorhinolaryngol 1997;254(Suppl 1):S18-9.

12 Pogrel MA, Schmidt B, Ammar A. The relationship of the buccal branch of the facial nerve to the parotid duct. J Oral Maxillofac Surg 1996;54:71-3.

13 Son ET, Choi HJ, Nam DH, et al. Analysis of anatomical relationship between Stensen's duct and buccal branch of facial nerve. Arch Craniofac Surg 2013;14:102-6.

14 Zenk J, Hosemann WG, Iro H. Diameters of the main excretory ducts of the adult human submandibular and parotid gland: a histologic study. Oral Surg Oral Med Oral Pathol Oral Radiol Endod 1998;85:576-80.

15 Iro H, Zenk J, Waldfahrer F, et al. Extracorporeal shock wave lithotripsy of parotid stones: results of a prospective clinical trial. Ann Otol Rhinol Laryngol 1998;107:860-4.

16 Zenk J, Koch M, Klintworth N, et al. Sialendoscopy in the diagnosis and treatment of sialolithiasis: a study on more than 1000 patients. Otolaryngol Head Neck Surg 2012;147:858-63.

17 Samani M, Hills AJ, Holden AM, et al. Minimally-invasive surgery in the management of symptomatic parotid stones. Br J Oral Maxillofac Surg 2016;54:438-42.

18 Capaccio P, Gaffuri M, Pignataro L. Sialendoscopy-assisted transfacial surgical removal of parotid stones. J Craniomaxillofac Surg 2014;42:1964-9.

19 Baurmarsh H, Dechiara SC. Extraoral parotid sialolithotomy. J Oral Maxillofac Surg 1991;46:127-32.

Received: September 15, 2016 - Accepted: December 12, 2016

Address for correspondence: M. McGurk, Department of Oral and Maxillofacial Surgery, Guy's Hospital, London, SE1 9RT. Tel. 020 7188 4349. E-mail: mark.mcgurk@kcl.ac.uk 